\title{
The Leather Trade in the Bassi of Naples
}

\section{Victoria Goddard}

\section{Introduction}

Since the early 1970 s there has been growing concern in Italy over the expansion of decentralised production. Decentralisation involves putting out all or part of the production process from a central unit to one or several other satellite units. This is a strategy adopted in response to factors such as a fluctuating or a highly competitive market, increased labour costs, trade union activity, or lack of capital investment. Decentralisation grants enterprises a greater degree of flexibility and manoeuverability, and allows a wellestablished firm to take indirect advantage of the employment conditions characteristic of the informal sector: low wages, no security of employment, no social benefits, no trade union presence.

As a consequence of the process of decentralisation, the Italian economy has a relatively high percentage of very small units of production. In other Western European countries the importance of this type of unit is decreasing, but in Italy 'artisan' units increased by 15 per cent between 1951 and 1961 and by 75 per cent between 1958 and $1968^{1}$ [Centro Studi Federlibro 1974]. There are, however, serious difficulties in establishing the real extent of such units and the nature of their relationship to the market. Some surveys indicate that the percentage of independent small units is declining: in 1960, for example, a Ministerial survey showed that 17 per cent of all units interviewed in the provinces of Milan and Sondrio produced for other enterprises. A study carried out in Lombardy ${ }^{2}$ in the early 1970 s showed that those artisan units producing part-products (representing 13 per cent of total artisan production) supplied 56 per cent of their produce to industrial units, 9 per cent to intermediaries and 20 per cent to other artisans.

The growing importance of small units in the Italian economy cannotbeexplainedinterms of thepersistence

\footnotetext{
1I use the term artisan according to its definition under Italian law, since this provides the basis for the collection of statistical data. The definition covered:

a) a unit which does not produce by assemblage and normally employs more that 10 dependents including the owner's family and excluding apprentices:

b) a unit which does not produce by assemblage but does not normally employ more than 5 dependents including the owner's family and excluding apprentices. and when the process of procution is not fully mechanised:

c) a unit which is active in arfistic production. traditional production and the production of garments made to measure.

${ }^{2}$ Regione Lombardia - Assessorato all Artigianato. Indagine Conoscitiva sull'Artigianato Lombardo. Milano. Dic 1972-Gen 1973. Quoted in
} Frey, 1973. of traditional forms, or by the presence of an economically backward, as distinct from a modern capitalist sector. Rather, it can be argued that the expansion of small units of production is bound up with the particular strategies of those Italian capitalist enterprises with which they are intimately linked. This is supported by the fact that small units increased during the period of the economic boom of the late 1950 s and early 1960 s and held their position during the subsequent recession, with the increase occurring not in the less developed areas of the country, but rather in and around the areas where capitalist manufacture is concentrated. Smallunitsof production must be understood in terms of their relation to larger formal sector units either because they must compete with such units or because they are closely bound up with the dynamics of such units through the process of decentralisation.

From the point of view of the small unit of production, acting as a sub-contractor to a larger firm may be the only means of entering a difficult or evasive market. These include both foreign and national markets where the small entrepreneur may lack the necessary contacts. The illegal status of the small unit makes access to the market even more difficult. In most cases the relationship is established on the basis of the weakness of the small scale unit, whether due to lack of capital and need for credit, or to difficulties in obtaining regular supplies of raw materials. Sometimes the small entrepreneur does not have sufficient capital to undertake the complete production process, and therefore specialises in only one aspect and is thereby obliged to establish a relation of dependence to other units.

But whether dependent or independent the small unit is subject to considerable competitive pressure, and a central element in its survival is the ability to call on cheap or unpaid labour. Such units therefore tend to rely on unpaid family labour, and on the labour of outworkers. Workers employed within the unit are usually young apprentices who are paid very low wages. Not only does the small unit have access to cheap labour, but tight control is maintained over those employed so that absenteeism is rare, conflict is largely contained and workers are likely to accept seasonal fluctuations in wages, delays in the payment of wages, etc. The key to the operation of the subcontracting process and of the survival of very 


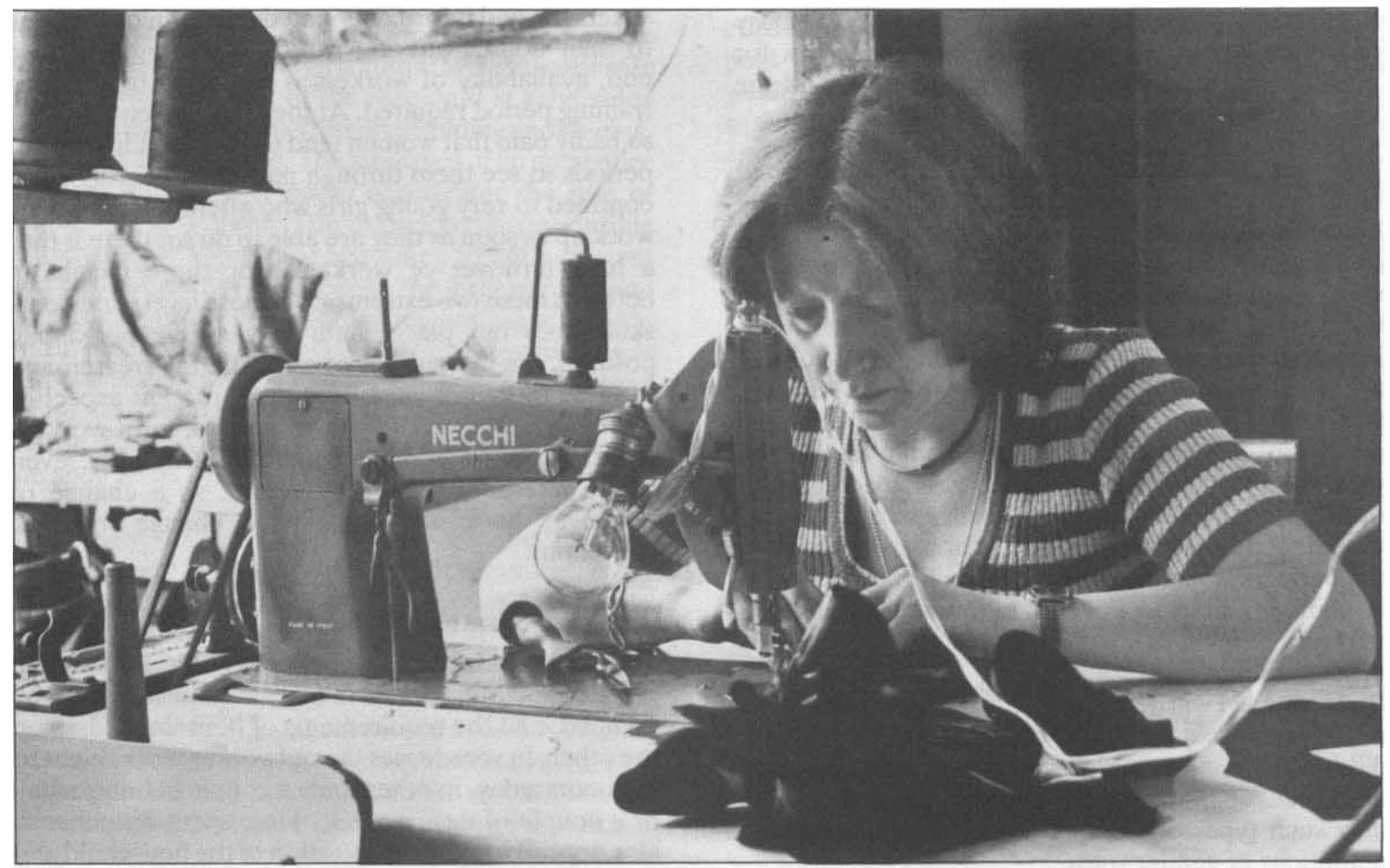

A team of outworkers in the shoe trade of Naples. The 'organizer' concentrates on sewing the leather uppers of the shoe, whereas assistants and apprentices carry out the preliminary operations of folding and glueing.

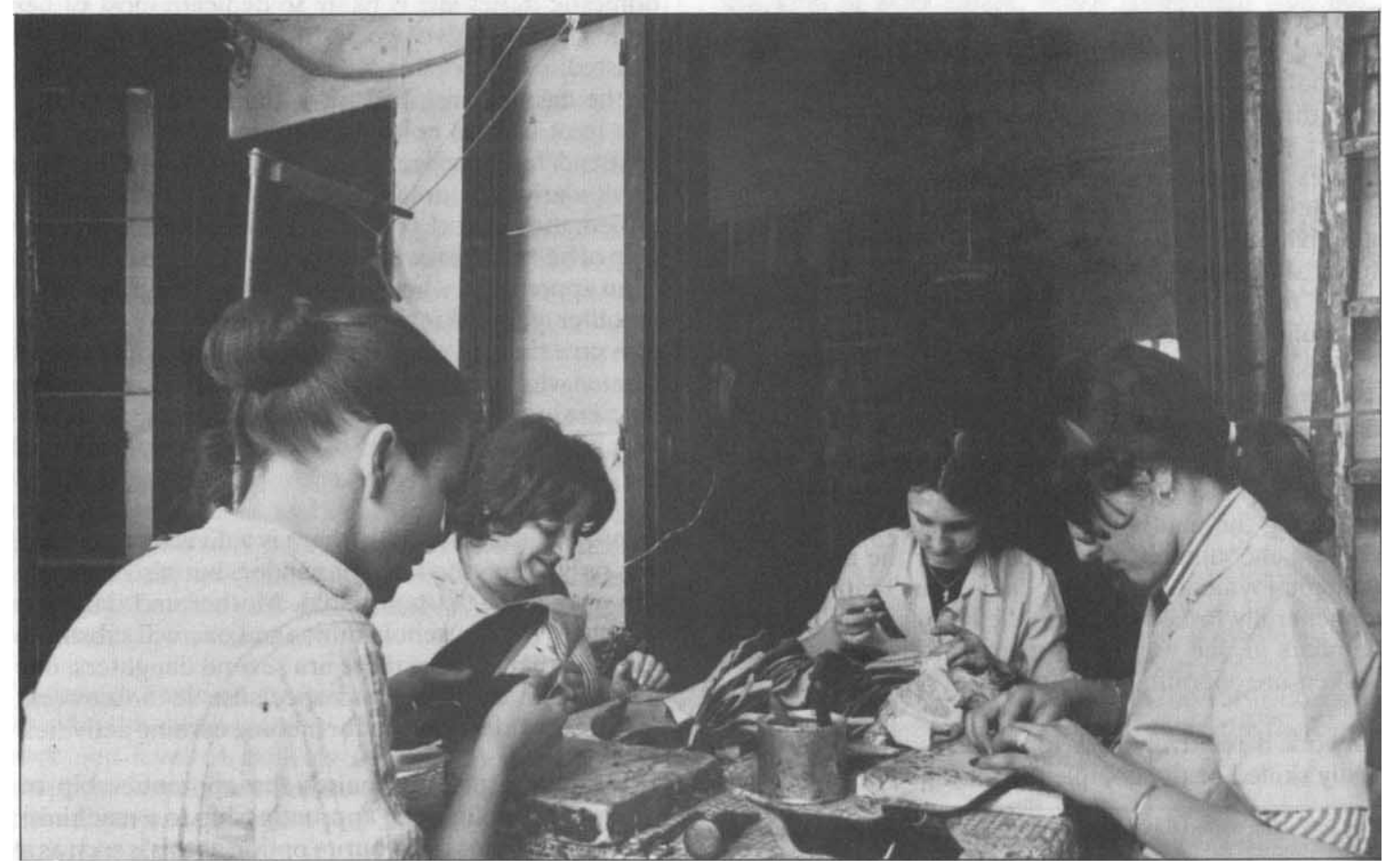


small units of production (1-20 workers) is the availability of family labour, the use of personal networks for recruitment, access to capital and markets, and the use of outworkers.

The outworker is a key figure in the survival of small units and in the decentralisation process, generally being employed not only by small artisan units, but also directly by medium and large scale enterprises as well. Regional surveys indicate that outwork is widespread, but is especially important in the more industrialised areas of the country, and that outworkers are predominantly women-estimates suggest between 90 and 98 per cent. Whereas the legal and ideological definition of artisan or small scale unit retains the possibility of independence-indeed this is the ideal-the outworker is by definition dependent and is little more than a factory worker working at home. In addition, the outworker almost always works illegally, and thus remains invisible to government, trade unions and surveys.

In this article I will describe briefly the work conditions of outworkers in the slums of Naples, the Bassi, and discuss the context within which outwork and petty entrepreneurship operate; in particular I will show how such types of work reinforce the predominant definitions of gender roles.

\section{The Outworker - the Case of Naples}

The city of Naples represents an intersection of the contradictions inherent in the Italian economic system. It is both a centre of absorption of rural immigrants from the impoverished hinterlands, and an important export point for labour power to Northern industrial centres and other centres in Europe and overseas. High levels of unemployment characterise all sectors of activity and the per-capita income is equal to twothirds of the national mean. From 1963 to 1971 there was a fall in the open demand for labour and in particular for female labour. The official employment figures, however, hide the high levels of underemployment and illegal employment. The city has a long tradition of homework and in particular of skilled outwork in the leather trades and it is in this trade that most of the outworkers interviewed were concentrated. ${ }^{3}$ Reflecting the national pattern, the majority of outworkers encountered were women, for the pressures of unemployment and low incomes mean that families are generally forced to utilise the labour of all family members in one way or another. It also means that workers are operating in a situation of surplus labour.

Outwork is relatively easy to find for workers at the highly skilled or the completely unskilled ends of the

\footnotetext{
${ }^{3}$ The following material is drawn from research carried out in Naples
} in 1976 and 1977 . spectrum, and informants stated that employers came to their houses offering work. At the highly skilled end, availability of workers is restricted by the long training period required. At the unskilled end, work is so badly paid that women tend to take it on for limited periods to see them through particular crises, or it is confined to very young girls who attempt to give such work up as soon as they are able to do so; there is thus a high turnover of workers. For those caught in between these two extremes, or whose level of personal skills does not place them in a strong bargaining position, the insecurities of work are far greater, and the fear of loss of work is an ever present aspect of their work relation. For these reasons, most workers prefer to avoid conflict with their employer, even where alternatives may be found, as a change of employer does not result in a change in work conditions.

\section{The Organisation of Work}

The work timetable of the outworker is carefully planned according to the family's income needs on the on hand, and the requirements of household tasks on the other. In some cases the outworker works eight to ten hours a day, in others only a couple of hours a day or a couple of days a week. Time spent on outwork also depends on the composition of the household and the division of labour within it - where the outworker has a daughter or kinswoman to take over the bulk of domestic duties she is likely to dedicate most of her time to productive work. She is also likely to be assistedinher productiveworkbyotherfamilymembers. In the case of unskilled work the whole family may join in at various points during the day-though the husband/father will rarely become involved. Children, particularly girls, are important helpers. If the work is skilled, the outworker may supplement the occasional help of her children with the more regulated assistance of an apprentice, who may be her own daughter, sister or other young kinswoman or neighbour. She may also save time by using the services of neighbourhood women who specialise in dealing with the bureaucracy for pensions and the like, and in suburban areas she may also use the services of women who specialise in the bulk buying of staples.

In most households then, there is a division of labour, not only along the lines of gender, but also between the women of the household. Mother and daughter will share the household duties and one will substitute for the other. Where there are several daughters, one will remain at home and specialise in housework, freeing the other women for income earning activities.

The family usually organises the apprenticeship of one or more daughters: apprenticeship to a machinist in the shoe trade is a favourite option as this is seen as a 
relatively secure area of employment and one which will not interfere with the girls' future tasks as housewife and mother. The task of the machinist is subdivided intoa manual phase which involves folding and glueing, and a later sewing phase. The assistance of an apprentice to carry out the first phase accelerates the rate of output of the worker. The outworker is responsible for paying the apprentice according to her judgment and to what is decided between the girl's parents and herself. Generally these payments are made weekly and are very low indeed, since the major motivation is that of learning a trade. Increasingly young girls attend school and their apprenticeship can only be carried out on a part-time basis. Most skilled outworkers in the shoe trade learnt their trade at a very young age (around eight or ten years) from other outworkers: their mothers, aunts, sisters or neighbours. In some cases they were introduced to factory work very early on and acquired their skills in a factory context, but in all these cases they had worked under the supervision of kin. The family's networks are mobilised to find work and training for their daughters, which means that girls almost inevitably work under supervision of trusted adults and that their employment is conditioned by the parents' obligations to friends and kin so that conditions of employment take second place to personal considerations.

The family is also likely to provide the girl with the tools of her trade: as part of her inheritance a young girl will frequently receive a sewing machine. This was widespread practice in the past when even factory workers were expected to provide their own machine. The outworker thus generally uses her own sewing machine. It is not uncommon for women workers leaving the factory to take with them a machine which is paid for by deductions from her wages as an outworker. This is often perceived as a favour but in fact, although it does solve the worker's immediate problem, it binds her to that employer until the machine is paid off and it provides the employer with an opportunity to get rid of old equipment. Older machines may require more outlay for repairs and may be slower than new ones. But since there seems to have been little change in the basic design of leather-sewing machines, they are rarely totally obsolete, and some workers claimed that their old models were in fact more reliable than newer ones. This is important since it means that the machinery necessary for shoe and glove-making is available to both workers and factories.

Payment is made on a piece rate basis but rates vary considerably, and not only according to the type of work and level of skill involved. Within the single category of machinists there were variations according to the experience of the worker and the characteristics of the employer-with very small units relying on cheap labour for survival generally, but not always, paid lower rates than the larger units catering for wealthier markets. Payment was usually on a weekly basis, often coinciding with the delivery of raw materials and the collection of finished goods. Delivery and collection is carried out by the employer in the case of very small units or by an employee of the larger units. It is also common for kin or neighbours working inside the factory to act as intermediaries.

Occasionally teams of women work together; such teams may consist of a mother and daughter, or a couple of sisters or kinswomen. They are relatively successful and usually have the added advantage of the help of young children and/or apprentices. They can increase their output to the point where they work simultaneously for several employers, which gives them a stronger bargaining position and a higher income. In two-woman teams the income is usually divided equally, but in the larger groups there is a hierarchy whereby the nominee, who tends to be more experienced and skilled, receives the payment and distributes it according to skill, task and hours worked. She is not seen as a 'boss'-her function is more that of supervisor, co-ordinator and in respect of apprentices, teacher as well.

One of the major advantages of outwork stressed by many outworkers themselves is the relative freedom this kind of work offers. When confronted with the pace of their work this appears to be something of a myth. Yet, in spite of the pressures of consignments, they are able to allocate their time in a relatively flexible way. In addition, they are working in their own space, without any form of direct supervision, and in many cases there is the advantage of chats with occasional visitors and passers-by, which can be carried out without interrupting work. Although the outworker is isolated in the sense that she is cut off from other workers, she is in most cases an integral part of her community. ${ }^{4}$ However, many outworkers did express an ideal preference for factory work or for 'pure' housework. Women who had given up factory employment did this in all cases as a result of family pressures-because of their duties as housewives, or because of their obligations as wives, daughters or fiancées. In other words, men exert a lot of pressure on women to give up factory work and take up work in the socially and morally safer context of their own homes, or in the home of a trusted kinswoman or neighbour. In fact, a considerable number of apprentices or assistants who were not related to the outworker by ties of kinship were future affines, that is, the fiancées of brothers, cousins or nephews.

\footnotetext{
${ }^{4}$ This is less so in the case of outworkers living in the outskirts of town.
} in apartment blocks and council flats. 


\section{Outworker or Entrepreneur?}

In a situtation where subcontracting and decentralisation have encouraged the reproduction and even expansion of very small units of production, there are differential patterns of non-factory employment for men and women. While such processes result in outwork for women, they seem to provide for men the possibility of a dependent or independent artisan or petty entrepreneur status. Why do women's attempts at greater control over their time and work result in outwork rather than independent producer status? The question must be understood in terms of definitions of gender and of the gender division of labour within the household and within and between trades.

Clearly the motivation behind the choice against factory work is different for men and for women. ${ }^{5}$ But in most cases encountered, male factory workers and petty entrepreneurs expressed a strong desire for 'being their own boss'. This desire for independence is coupled with the hope that their efforts will bring them success and economic well-being, and provide the means to break out of the poor living conditions to which they are condemned as factory or, worse, workshop workers. In reality, the ideal of independence and economic success is rarely fulfilled. In order to secure a minimum income a burdensome pace of work is imposed on the small unit from the outset. Frequently it is forced, either at inception, or as a result of operational difficulties, to enter a subcontracting relationship. This involves the loss of independence of the unit, but at least has the advantage of guaranteeing the entrepreneur's internal control.

While independence for the male worker is defined largely in the sphere of work, for women the relevant sphere is the household. A woman's aspirations to independence relate to a desire for relative autonomy within the context of her household duties. Her autonomy is therefore oriented towards the smoother functioning of two opposing roles: housewife and 'worker'. A woman's choice is conditioned by her obligations within the household both as an income earner and as a provider of household services. A man is also conditioned by his role in the household and his obligation to provide for the family, but this obligation pre-supposes his complete exclusion from household tasks and thus grants him greater freedom to pursue his ambitions, both in the sense that he is not tied to the household and the neighbourhood, and that he has more time at his disposal. If anything, a young woman's struggle for personal freedom and autonomy will not be directed against the factory but against the household,

\footnotetext{
It is important to note that the lack of employment opportunities in Naples is in itself a factor in favour of setting up one's own business and therefore may not represent an alternative to. or rejection of.
} factory work. which is seen as the principal source and area of their control. For single women parental control is identified asthesource of oppression, and factory work represents a means of escaping from or at least alleviating this control. At marriage however, and with fullacceptance of the marital role, this will change. Marriage is also seen and used as a means of escaping from parental control and establishing an area of autonomy by setting up one's own home. Restrictions imposed by the marital home are not seen in the same way as are the cases of obligations arising in the parental home, since this is a woman's own territory and she perceives the functioning of 'her' home to be primarily in her own interest.

The division of labour by gender results in important differences in the access for men and women to resources, whether these be capital, skill or labour. There are, of course, independent productive activities requiring very limited capital and skills which are frequently resorted to by the unemployed; but these usually provide low returns and little stability and are unlikely to constitute a long-term activity. In the leather goods industries which cater for the local market but also offer opportunities at a national and international level, the entry requirements are much harsher. Access through inheritance is essentially discriminatory, since the artisan unit will be passed on to a son or other male kin. Where inheritance is not relevant, an individual attempting to establish an independent unit must fulfil certain minimum requirements: s/he must have access to capital; must have an adequate knowledge of the trade; and must have access to cheap labour.

Capital is usually acquired through an early retirement or redundancy payment. Frequently the ex-employer will provide machinery and credit which will be paid back with work. Alternatively loans may be negotiated through banks or special state funds. Men are more likely than women to be successful in such negotiations because they are perceived as having greater business credibility, and they are more likely to gain the support of appropriate backers. In either case the new entrepreneur is unlikely to be able to provide the installations necessary to operate a complete process and is thus likely to concentrate initially on operations which are manual, or which require relatively cheap machinery.

The success of the new unit and its capacity to expand is to some extent dependent on the entrepreneur's knowledge of the trade, since someone setting up their own unit must know the entire production process. Given the sexual division of labour within the trade, women are excluded from knowledge of very crucial phases of production. Men who have been apprenticed 
to artisans learn the entire process-even though they may specialise in one task they have sufficient overall knowledge to control and direct the entire process. Women may achieve high levels of skill and take a great deal of pride in their work, but their knowledge is extremely compartmentalised. This is increasingly becoming the case also for men who are factory trained.

Another important factor is that men have a greater capacity to recruit labour. They can call on kin or past work colleagues for specialised male tasks and most importantly, they can count on the labour of wives and children and perhaps of other household members and other kin. A woman is unable to command the labour of the entire household. She is able to draw on the female labour pool, but the labour of sons, husband and male kin remain beyond her reach. Whereas the entire household is likely to organise itself around the work of the male household head it is very unlikely to organise itself around the tasks of a woman. Thus, a woman is limited by the differential distribution of authority and decision-making powers in the household.

Contacts are crucial not only to draw cheap labour power but also to secure credit and loans and to ensure that the product is commercialised. Because of their greater freedom of movement, men acquire a far wider network and are in a better position to build up contacts which could be economically useful. Women are far more restricted to kin and neighbourhood networks, and even if these expand as a result of factory work, trade union activity, etc their relationships with men are severely limited by definitions of gender and appropriate forms of interaction, and are not conducive to the kinds of relationships such as friendship and partnership which can become instrumental. Since in most cases it is men who hold key positions in the various relevant institutions, women are excluded from the personal networks which are so important for the establishment and survival of small enterprises.

Clearly some women are interested in expanding and improving their economic activities. This they generally do by teaming up with other women and taking on a number of apprentices and assistants. Although the cases encountered were quite successful and required a great deal of organisational capacity, they did not become independent in the sense in which most small artisans or other units are. They were simply expanded outwork units. Further expansion is thus limited to multiplying the single tasks, whereas there are success stories (though few) of male-headed small units which expand and become complete process units, sometimes with independent access to the market.

\section{Conclusion}

I have attempted to illustrate the significance of personal relations for the operation of economic activities in the socio-economic context of Naples. Both from the point of view of the worker and from that of the entrepreneur personal contacts are important instruments. Availability of work, access to capital, access to markets, survival and success, are to a large extent contingent on an individual's capacity to mobilise personal networks. Such networks provide the links between the informal and the formal sectors.

Definitions of gender roles and of male and female spheres (both social and physical) result in differential access to these personal networks. The differences are quantitative, in that women are restricted to the household and neighbourhood while men may venture further afield and may succeed in establishing relations which cut across class lines through various forms of unbalanced friendship (such as patron-client relations). The differences are also qualitative, for gender defines the content and characteristics of relationships both within the household and outside it. Within the household, relations are based on the unequal distribution of authority along the lines of age and gender. This means that adult men and women have a different capacity to command the labour of other household members, and that women's exercise of authority is limited to very small children and to other female household members. The content of relations outside the household is also largely predetermined. Friendship does not, except in the most formalised cases, cross the boundaries of gender. Thus, the very nature of the social network and the content of relations within it operate to reinforce the woman's subordination to the household in her appropriate gender roles. The conflict arising from these roles and from the household's need for income therefore finds its resolution in the outwork relation.

\footnotetext{
References

Centro Studi Federlibro, Fim, Sism-Cisl di Verona, 1974, Piccola Azienda, Grande Sfruttamento, Bertani Editori. Verona

Frey, L, 1973, 'Dal lavoro a domicilio al decentramento dell'attivita produttiva', Quaderni di Rassegna Sindacale. $44 / 45$
} 